\title{
Problems of teaching foreign students in mixed groups
}

\author{
Elena Romualdovna Laskareva ${ }^{1}$, Alina Aleksandrovna Pozdnyakova ${ }^{2 *}$, Tatyana Nikolayevna \\ Bazvanova $^{2}$, Daria Aleksandrovna Dmitrieva ${ }^{2}$, and Tatiana Pavlovna Chepkova ${ }^{3}$ \\ ${ }^{1}$ Saint Petersburg State University, Faculty of Philology, Moscow, Russia \\ ${ }^{2}$ The Kosygin Russian State University, Institute of International Education, Moscow, Russia \\ ${ }^{3}$ Moscow Pedagogical State University, Institute of Philology, Moscow, Russia
}

\begin{abstract}
The article analyzes the problems associated with teaching foreign students in mixed groups. A mixed group is a formally isolated part of the educational institution cohort that possesses such characteristics as: 1) a fixed heterogeneous ethno-cultural composition, 2) a different level of preparation of students for mastering the disciplines of the general educational program, 3) common cognitive interests and a single educational content in the current period of time; 4) joint educational activities under the guidance of the same teachers, 5) a single period of study. This article aims to highlight the range of language problems that hinder the development of general education programs by foreign students when studying as part of a mixed group. Since the structure of language difficulties varies for different categories of foreign citizens (foreigners with an initial level of proficiency in Russian, foreign speakers, bilinguals), it is important to have a differentiated approach to regulating the educational process and specially organized training taking into account the ethnic and linguistic needs of all members of the group. A differentiated approach to learning, building an individual way of each group member development allows mobilizing cognitive interests and motivating participants in the educational process. The development of specific recommendations to overcome the possible negative impact of a mixed group on the process of obtaining subject knowledge by foreign students is an important methodological task that requires further study.
\end{abstract}

Keywords: educational process, foreign student, mixed group, bilingualism, language attrition

\section{Introduction}

It is necessary to figure out that a mixed group is a formally isolated part of the educational institution cohort that possesses such characteristics as: 1) a fixed heterogeneous ethno-cultural composition, 2) a different level of preparation of students for mastering the disciplines of the general educational program (EP), 3) common cognitive interests and a single educational content in the current period of time; 4) joint educational activities under

*Corresponding author: apozdnyakova@live.ru 
the guidance of the same teachers, 5) a single period of study. These characteristics define a mixed group as an organizational unit of the educational space, that is, a kind of "bureaucratic, impersonal structure". However, a mixed group is the primary team for its members; therefore it assumes cohesion, integration into the educational process and "equality" of all the members in obtaining knowledge. This last point seems quite controversial and raises questions that the authors of this article would like to consider further.

This study aims to highlight the range of language problems that hinder the development of general education programs by foreign students when studying as part of a mixed group.

The following study tasks can be considered as follows: 1) analysis of the structure of language difficulties for different categories of foreign citizens arriving to Russian universities; 2) analysis of problems related to the organization of the educational process; 3) development of recommendations that aim to overcome the possible negative impact of a mixed group on the process of obtaining foreign students subject knowledge.

\section{Methods}

In order to implement the aim and tasks, the following methods were used: theoretical analysis of psychological and pedagogical, sociological, linguistic literature on the research problem; a study of the survey bilinguals (children and adults) in Russia and abroad [1-14]; questionnaires, testing, surveys of bilingual students studying at Moscow universities and St. Petersburg universities; analysis of expert opinions and procedures for assessing the quality of education in groups; analysis of statistical data.

The diagnostic measures are based on projective research methods: the method of semantic differential [15], which allows determining the emotional attitude of the subjects to the manifestations of language attrition; the method of unfinished sentences (MUS), which provided material for analyzing the status characteristics of languages in the minds of bilingual speakers. The authors also used a method of expert assessment of the personality of a bilingual student, which allows identifying trends in the communicative behavior of bilingual speakers. The created expert tools have been tested in practice during diagnostic activities at the universities of Moscow and St. Petersburg.

\section{$3 \quad$ Results}

The main result of the conducted research can be considered a qualitative and quantitative assessment of the range of language difficulties faced by foreigners during the period of study in a mixed group. The degree of influence on the success/failure of the assimilation of subject knowledge of such factors as 1) heterogeneity of the ethno-cultural composition of the group, 2) the level of preparation of students to master the disciplines of the EP, 3) the presence/absence of general motivation, 4) the unity of educational content, 5) the influence of ethnic scientific schools in a particular subject area.

Since the structure of language difficulties varies for different categories of foreign citizens (foreigners with an initial level of proficiency in Russian, foreign speakers, bilinguals), a differentiated approach to the organization of the educational process is important. In this sense, the authors rely on the ideas of the British linguist P. Skehan, who insisted on paying more attention to how foreign language learners differ. He was arguing that "their diversity and individuality are a decisive factor in language acquisition" [16]. 
The recommendations developed in the course of the study can form the basis of measures aiming to overcome the possible negative impact of a mixed group on the process of obtaining subject knowledge by foreign students.

\section{Discussion}

The foreign student cohort in a modern university is extremely heterogeneous in its composition. In addition to those who have graduated from preparatory departments and preparatory faculties, foreign speakers - persons who study at the first courses of universities are those who "use one functional language as a tool of cognition" [3], and bilinguals who speak two or more languages learned "in childhood either in natural conditions, ... or by early inclusion in another language environment" [3].

Getting into a mixed group, bilinguals are forced to master general education disciplines in a situation of some kind of language expansion - together with native Russian speakers. The balance of the languages in the competence of the media may vary one way or the other hand - it is a known fact, is much less common and is, therefore, an area of interest for many researchers "balanced bilingualism or multilingualism" [6-8, 12, 13, 17-19].

The problems faced by bilingual students while studying in mixed groups are quite specific and require special consideration [20]. Conditionally, they can be divided into two categories, the first of which is problems related to the language environment of the individual, the second is problems related to the organization of the learning process itself. The solution of these problems requires the adoption of special measures and the implementation of measures that contribute to the successful development of disciplines by this category of trainees.

Of the problems of the language environment, two stand out as the most frequent in the teaching practice: 1) the weakening of the native (or well-mastered earlier) language (attrition) and 2) the decrease in the quality of perception of the Russian language in standard educational situations.

Therefore, M. Schmid defines language attrition as "a non-pathological weakening of the language previously learned by an individual" [7]. This weakening, according to the researcher, "proceeds most intensively at the beginning, and then goes into decline" [21], however, it may represent "a tangible symptom of disconnection and rupture with the natural language environment" [7]. The processes of destruction of the native or well-mastered language system are observed quite often in people who have been living in bilingualism or multilingualism for a long time $[22,23]$. If to talk about the beginning of bilingual education in Russia, it is necessary to declare that individual cases of language attrition in the native language of students begin manifesting themselves by the end of the first term. At the same time, only productive skills (correct word usage, word formation, phrase formation) weaken; receptive skills (recognition and understanding of lexical units when perceiving sounding speech or in printed text) remain unchanged for a long period, even if inactive use of the native language. This position is reflected in the works of M. Schmid, who proves that the influence of factors such as frequent use of language and deeper familiarity with it is much less significant for attribution than is commonly believed. A significant role in the process of weakening the national language is played by the speaker's attitude to the community of origin - his historical homeland. That is, in a situation where motivation and interest in the culture of the country of the studied language come to the fore, the national language takes a subordinate position and fades into the background [6]. 
Of the notable manifestations of language attrition, recorded by the authors of this article during a detailed experiment to identify the language preferences of bilingual students, the most common are: 1) a decrease in the accuracy of word selection (18\%);2) an increase in the frequency of pauses between words $(22 \%)$; 3$)$ the appearance of repetitions and hesitations while word choosing $(15 \%) ; 3)$ the omission of words and fragments of sentences ("fragmentary forgetting") $(12 \%) ; 4)$ the appearance of lexical borrowings and substitutions $(28 \%) ; 5)$ the appearance of cripples $(6 \%) ; 6)$ the cessation of replenishment and development of the lexicon of the source language (noted by $12 \%$ of subjects; $39 \%$ could not evaluate this criterion); 7) interference at the syntactic and (less often) morphological levels $(11 \%) ; 8)$ weak interference at the phonetic level [the appearance of sounds not characteristic of the national language, accent] $(6 \%)$.

The analysis of the quality of perception of the expansive (Russian) language in bilinguals reveals: 1) a decrease in the speed of perception of sounding speech $(16 \%) ; 2$ ) faults in the recognition of polysyllabic words in sounding speech and in the text $(12 \%) ; 3)$ difficulties in recognizing complex syntactic constructions when reading $(8 \%)$; 4) violations in the evaluation of perceived fragments of speech (9\%).

An important factor in the appearance of this or that type of violations are the conditions in which the assimilation of languages (national and Russian) and the "quality" of the formed "bilingual skill" took place. The language of the environment, as a rule, plays a leading role in this, and this is certainly a positive moment for the rapid assimilation of everyday vocabulary. However, in the situation of the educational process, the accumulated speech experience is often able to have a negative impact: "In some categories of bilinguals, second language proficiency is superficial, sometimes vulgarized, and academic norms are hardly imposed on their established stereotypes" [24].

The other side of intra-group interaction is foreign students, who often have a level of training in the Russian language at a level below B1. Many researchers say that the language of foreigners in the general group forms its own "language context", which is felt by bilinguals more clearly than by native speakers. The language environment has a significant impact on the speech behavior of bilinguals $[25,26]$.

The problems associated with the organization of the educational process of students of mixed groups are quite standard. This is the monochromacy of the content, which does not allow them to build an individual trajectory of development of a foreign student (bilingual, foreign speaker); insufficiency of ethnically oriented practices; lack of flexibility in assessing the level of formed competencies, etc. At the same time, most researchers agree that the correct organization of the educational process is important for both L2 (Russian) and L1 (national) languages [21].

The importance of special education in mixed multiethnic groups was experimentally proved by a group of scientists led by Professor T. Teishner [27]. Other academical specialists come to a similar conclusion, emphasizing that the effectiveness of learning increases if the ethnic needs of all group members are taken into account, on the one hand, and the nature of the "dominant languages", on the other [28]. In addition, learning is carried out more successfully the closer it is in its psychological mechanisms to the process of natural mastering of the native language $[9,29,30]$.

\section{Conclusion}

Thus, the ethnocultural heterogeneity, the different levels of language training of the foreign contingent often act as factors complicating the group work of the teacher, aimed at the joint development of general education programs by students and obtaining deep subject 
knowledge. In this case, the authors of this article can and should talk about the formation of a mechanism aiming to overcome the difficulties of inter-language interaction and the organization of differentiated learning. A differentiated approach to learning, building an individual trajectory of development of each member of the group allows you to mobilize cognitive interests and motivate participants in the educational process.

\section{References}

1. S.N. Zeitlin, Cogn Stud Lang, 22, 908-910 (2015)

2. S.N. Zeitlin, Izvestiya - RSPU, 196, 7-17 (2020). https://doi.org/10.33910/1992-6464-2020-196-7-17

3. E.A. Khamraeva, Sci School, 3, 29-40 (2018)

4. E.A. Khamraeva, A.V. Gusev, World Rus Word, 4, 105-110 (2020). https://doi.org/10.24411/1811-1629-2020-14105

5. I.V. Shcheglova, Phil Sci. Quest Theory Prac, 9(87(2)), 410-414 (2018)

6. M.S. Schmid, Language attrition. (Cambridge University Press, Cambridge, 2011)

7. M.S. Schmid, Babylonia, 2, 9-12 (2008)

8. M.S. Schmid, On L1 attrition and the linguistic system, in EUROSLA Yearbook 9, 212-244 (2009)

9. C. Bergmann, S.A. Sprenger, M.S. Schmid, Acta Psy, 161, 25-35 (2015). https://doi.org/10.1016/j.actpsy.2015.07.015

10. C. Ellis, et al., Soc Cogn Affect Neurosci, 10, 1392-1396 (2015). https://doi.org/10.1093/scan/nsv028

11. E. Blom, et al., Frontiers Psy, 8, 552 (2017). https://doi.org/10.3389/fpsyg.2017.00552

12. M. Lehtonen, et al., Psy Bul, 144(4), 394-425 (2018). https://doi.org/10.1037/bul0000142

13. M. Antoniou, Ann Rev Ling, 5(1), 395-415 (2019). https://doi.org/10.1146/annurev-linguistics-011718-011820

14. Lopez-Beltran, et al., Sec Lang Res, 12, 1-32 (2021). https://doi.org/10.1177/0267658321992461

15. Ch.E. Osgood, Method and Theory in Experimental Psychology. (Oxford, 1956)

16. P. Skehan, Individual differences in second-language learning. (Edward Arnold, London, 1989)

17. P.E. Dussias, N. Sagarra, Biling Lang Cogn, 10, 101-116 (2007). https://doi.org/10.1017/s1366728906002847

18. N. Snape, T. Kupisch, Second Language Acquisition: second language systems. (Palgrave Macmillan, London, 2017)

19. J. Treffers-Daller, Ann Rev Ling, 5, 375-393 (2019). https://doi.org/10.1146/annurevlinguistics-011817-045554

20. Yu.P. Zinchenko, L.A. Shaigerova, A.G. Dolgikh, O.A. Savelyeva, Moscow Univ Psy Bul, 1, 174-194 (2019). https://doi.org/ 10.11621/vsp.2019.01.174

21. M.S. Schmid, T.H. Mehotcheva, Dutch J App Ling, 1(1), 102-124 (2012)

22. G. Chamorro, A. Sorace, P. Sturt, Biling: Lang Cogn, 19(3), 520-532 (2016). https://doi.org/10.1017/ S1366728915000152 
23. A.S. Malyshevskaya, et al., Mod Foreign Psy, 10(1), 111-124 (2021). https://doi.org/10.17759/jmfp.2021100111

24. A.A. Pozdnyakova, Sci School, 3, 13-17 (2011)

25. M. Medeiros, Ethnicities, 17(5), 627-645 (2017). https://doi.org/10.1177/1468796815608878

26. J.S. Siegel, Ethnolinguistic Communities, Ethnolinguistic Conflict, and Other Conflict Situations, in Demographic and Socioeconomic Basis of Ethnolinguistics. 299-241 (Springer, Cham.2018). https://doi.org/10.1007/978-3-319-61778-7_9

27. V. Volterra, T. Taeschner, J Child Lang, 5, 311-326 (2007)

28. C.A. Bogulski, K. Bice, J.F. Kroll, Biling: Lang Cogn, 22(5), 1052-1067 (2018). https://doi.org/10.1017/S1366728918000858

29. M.C. Frank, M. Braginsky, V. Marchman, D. Yurovsky, Variability and consistency in early language learning. (The MIT Press, Cambridge, 2021). https://doi.org/10.7551/mitpress/11577.001.0001

30. M.C. Frank, M. Braginsky, D. Yurovsky, V.A. Marchman, J Child Lang, 44(3), 677-694 (2017). https://doi.org/https://doi.org/10.1017/S0305000916000209 